\title{
Myocardial connexin-43 and PKC signalling are involved in adaptation of the heart to irradiation-induced injury: Implication of miR-1 and miR-21
}

\author{
Csilla Viczenczova ${ }^{1}$, Barbara Szeiffova Bacova ${ }^{1}$, Tamara Egan Benova ${ }^{1}$, Branislav Kura ${ }^{1}$, \\ Chang Yin ${ }^{2}$, Peter Weismann ${ }^{3}$, Rakesh Kukreja ${ }^{2}$, Jan Slezak ${ }^{1}$ and Narcis Tribulova ${ }^{1}$ \\ ${ }^{1}$ Institute for Heart Research, Slovak Academy of Sciences, Bratislava, Slovak Republic \\ ${ }^{2}$ Division of Cardiology, Medical College of Virginia, Virginia Commonwealth University, Richmond, Virginia, USA \\ ${ }^{3}$ Faculty of Medicine, Institute of Anatomy, Comenius University, Bratislava, Slovak Republic
}

\begin{abstract}
Intercellular connexin-43 (Cx43) channels are essential for electrical coupling and direct cardiac cell to cell communication to ensure heart function. Expression of $\mathrm{Cx} 43$ is altered due to stressful conditions and also affected by the alterations in extracellular matrix. We aimed to explore the effect of chest irradiation on myocardial expression of $\mathrm{Cx} 43$ and miR-1 which regulates GJA1 gene transcription for $\mathrm{Cx} 43$. Implication of miR-21 that regulates expression of extracellular matrix proteins and PKC signalling that may affect $\mathrm{Cx} 43$-mediated coupling was examined as well. Western blot and real-time PCR analyses revealed that six weeks after the exposure of healthy Wistar rats chest to single irradiation of 25 Gy significant myocardial alterations were observed: 1) increase of total Cx43 protein expression and its functional phosphorylated forms; 2) suppressed levels of miR-1;3) enhanced expression of PKC $\varepsilon$ which phosphorylates $\mathrm{Cx} 43$; 4) increase of miR-21 levels; 5) increase of PKC $\delta$ expression. These results suggest that irradiation causes post-transcriptional regulation of myocardial Cx43 expression by miR-1 possibly through miR-21 and PKC signalling. We conclude that single dose of irradiation has the potential to enhance myocardial intercellular communication that might be beneficial for the heart that needs to be investigated in details in further studies.
\end{abstract}

Key words: Irradiation injury - Rat heart - Connexin-43 - miR-1 - miR-21 - PKC

\section{Introduction}

Myocardial synchronization and a proper heart function depend on gap junction connexin-43 (Cx43) channels that are essential for electrical coupling between cardiomyocytes and direct molecular signal propagation (Severs et al. 2008). Cardiac cell-cell communication is also important for the regulation of cell growth, differentiation, apoptosis and adaptation of differentiated cardiac cells. Numerous endogenous and exogenous factors can modulate $\mathrm{Cx} 43$ channels function to enhance or inhibit intercellular communication in both physiological and pathological conditions (Salameh and

Correspondence to: Narcis Tribulova, Institute for Heart Research, Slovak Academy of Sciences, Dubravska cesta 9, POBox 104, 84005 Bratislava, Slovak Republic

E-mail: narcisa.tribulova@savba.sk
Dhein 2005; Tribulova et al. 2015). Importantly, tumor promoters and oncogenes inhibit coupling, which activate proliferation while anti-tumor compounds and anti-oncogene drugs can reverse this process (Salameh and Dhein 2005).

Radiotherapy using heavy-ions is frequently applied for treating cancer. The expression of $\mathrm{Cx} 43$ is highly sensitive to ionizing radiation. Even low dose of irradiation induces a significant elevation of $\mathrm{Cx} 43$ in a variety of cell types (Azzam et al. 2003). Radiation up-regulates $\mathrm{Cx} 43$ in both intact and infarcted rabbit heart ventricle (Amino et al. 2006). Consequently, enhanced coupling is associated with long-lasting protection of the heart from malignant arrhythmias (Amino et al. 2010). Nevertheless, the mechanisms responsible for the radiation-induced $\mathrm{Cx} 43$ up-regulation are not known. To this context, it is interesting to note that microRNA-1 (miR-1) is target GJA1 gene that encodes Cx43 (Yang et al. 2007) and elevated miR-1 represses Cx43 expression in 
viral myocarditis (Xu 2012). In addition, miR-1 regulates cardiac cell death by targeting Bcl-2 and over-expression of miR-1 induces apoptosis (Tang et al. 2009). Irradiation affects distinctive microRNAs in various tissues (Khan et al. 2013); however, it is not known if it may affect miR-1 levels in the heart. We hypothesize that down-regulation of miR-1 might result in up-regulation of myocardial Cx43 in response to irradiation.

MicroRNAs fundamentally influence the pathogenesis of various events (Kukreja et al. 2011), including adverse cardiac remodelling such as hypertrophy and fibrosis (van Rooij et al. 2012). These myocardial alterations compromise cell-to-cell contacts and $\mathrm{Cx} 43$ channels mediated communication in diseased or aged heart and promote the occurrence of malignant arrhythmias (Tribulova et al. 2008; Jansen et al. 2012; Radosinska et al. 2013). Fibrotic remodelling is attributed to miR-21 that is specifically enriched in cardiac fibroblasts promoting their activation and induction of extracellular signal-regulated signalling pathway (Thum et al. 2008). Protein sprouty homolog 1 (Sprouty1) as well as phosphatase and tensin homolog (PTEN) are identified as direct targets of miR-21. They regulate the expression of extracellular matrix metalloproteinase-2 (MMP-2) (Bauersachs 2012). In contrast with the detrimental effects of over-expression of miR-21 in cardiac fibroblasts there is evidence that up-regulation of myocardial miR-21 early after myocardial infarction confers the cardioprotection by suppressing apoptosis, inflammation and necrosis hence promoting survival (Yin et al. 2009; Bauersachs 2012; Quin et al. 2012; Toldo et al. 2014). Nevertheless, it remains unknown whether the expression of miR-21in the heart is altered following irradiation.

Numerous reports include ours suggest that one of the important pathways implicated in the modulation of heart function is PKC signalling (Steinberg 2004; Lin et al. 2008). It can modulate $\mathrm{Cx} 43$-mediated intercellular communication, cardiac remodelling and viability. Therefore, it is interesting to understand whether PKC would be altered in response to radiation.

Based on this background information, we designed this study to elucidate the impact of irradiation on the heart and to relate it with potential alterations in the expression of $\mathrm{Cx} 43, \mathrm{miR}-1, \mathrm{miR}-21$ and protein kinase $\mathrm{C}$ (PKC).

\section{Materials and Methods}

All procedures were approved by the Institutional Animal Care Commitee. Male Wistar rats were obtained from Velaz Praha (Czech Republic) and maintained on a 12:12-h light/ dark cycle with free access to food and water. Three-monthold animals $(n=12)$ were anesthetized with thiopental (65 $\mathrm{mg} / \mathrm{kg}$ b.w.) followed by irradiation with single dose of 25
Gy given locally on mediastinal area at the level of heart using $5 \mathrm{MeV} / 1 \mathrm{~kW}$ electron linear accelerator UELR 5-1S with tungsten converter to X-rays (Producer NIIEFA St. Petersburg, RF) as previously described (Mézešová et al. 2013). Control animals $(n=12)$ were shielded with lead plates. A single dose of $25 \mathrm{~Gy}$ to the rat chest corresponds to the therapeutic dose of irradiation commonly used in patients. Six weeks later the hearts were excised from anesthetized animals, rinsed with ice-cold physiological saline, weighed, frozen in liquid nitrogen, and stored in freezer until analysis. Left ventricular tissue was taken for analysis of $\mathrm{Cx} 43$ and PKC expression using Western blotting.

MicroRNA reverse transcription and TaqMan-based $q R T$ $P C R$ analysis for estimation of $m i R-1$ and $m i R-21$

Total RNA including small RNA was isolated from frozen left ventricular tissue of control and irradiated Wistar rats using miRNA mini kit according to the manufacturer's protocol (QIAGEN Sciences, MD, USA). Concentration and purity of the isolated RNA was checked using Nanodrop ND-1000 spectrophotometer (Agilent technologies, CA, USA). Briefly $10 \mathrm{ng}$ of total RNA was subjected for reverse transcription reaction with miRNA specific RT primers using microRNA reverse transcription kit (Applied Biosystems, CA, USA) in accordance to manufacturer's instructions. Real time PCR was performed using Roche Light cycler 480 II (Roche Applied Science, IN, USA). Taqman miRNA assay probe (Applied Biosystems, CA, USA) was applied to determine the expression level of miR-1 and miR-21. To normalized RNA content, endogenous U6 small RNA was used. Reverse transcription was performed using stem loop specific microRT primers under following condition: $16^{\circ} \mathrm{C}$ for $30 \mathrm{~min} ; 42^{\circ} \mathrm{C}$ for $30 \mathrm{~min}$ and $85^{\circ} \mathrm{C}$ for $5 \mathrm{~min}$. The obtained $\mathrm{cDNA}$ was diluted in 1:3 ratios and subjected to real-time PCR using Taqman amplicon specific assay probe under the following PCR cycle condition: $95^{\circ} \mathrm{C}$ for $10 \mathrm{~min} ; 95^{\circ} \mathrm{C}$ for $15 \mathrm{~s}$ and $60^{\circ} \mathrm{C}$ for $60 \mathrm{~s}$.

\section{Western blotting for CX43, PKCE and PKC $\delta$ expression}

Isolated left ventricular samples ( $n=6$ per group) were powdered and solubilized in SB20 (20\% SDS, $10 \mathrm{mmol} / \mathrm{l} \mathrm{EDTA,}$ $0.1 \mathrm{~mol} / \mathrm{l}$ tris(hydroxymethyl)aminomethane (TRIS), $\mathrm{pH}$ 6.8) by sonicator UP $100 \mathrm{H}$ (Hielscher, Teltow, Germany). Total proteins $(10-40 \mu \mathrm{g})$ from each sample were separated by SDS-PAGE on $10 \%$ acrylamide gels, transferred onto a nitrocellulose membrane and blocked with 5\% non-fat dry milk in Tris-buffered saline. For determination of $\mathrm{Cx} 43$, the membrane was incubated with primary rabbit polyclonal antibody (diluted 1:2000; Anti-Connexin 43C 6219; Sigma-Aldrich, St Louis, Missouri, USA). For determination of PKC $\varepsilon$ the membrane was incubated with primary rabbit 
polyclonal antibody (C-15, sc-214) and anti-PKC $\delta$ (diluted 1:1000; C-17, sc-213; Santa Cruz Biotechnology Inc., Dallas, Texas, USA) overnight at $4^{\circ} \mathrm{C}$ followed by further incubation for $1 \mathrm{~h}$ at room temperature with the secondary donkey antibody (1:2000 peroxidase labeled anti-rabbit immunoglobulin; Amersham Biosciences, Piscataway, New Jersey, USA). The densitometric analysis for the corresponding band was done using Carestream Molecular Imaging Software (USA).

\section{In-situ myocardial immunolabeling of Cx43}

Cryostat sections from the left ventricle were used for insitu immunodetection of $\mathrm{Cx} 43$ using mouse monoclonal anti-Cx43 antibody (Chemicon International, Inc.) and secondary FITC-conjugated goat anti-mouse antibody. Immunostained sections were examined using fluorescence microscope (Axiostar; Carl Zeiss, Jena, Germany) and images were acquired digitally for subsequent quantitative image analysis (Soft Imaging System, GmBh, Germany). Twenty randomly selected test areas were investigated per heart. From each test field a histogram of $\mathrm{Cx} 43$ fluorescence intensity was obtained and used for the calculation of $\mathrm{Cx} 43$ signal. The area of positive $\mathrm{Cx} 43$ labelling was defined as the number of pixels with the $\mathrm{Cx} 43$ signal intensity exceeding a threshold of 30 on the $0-255$ gray scale. Total number of $\mathrm{Cx} 43$ positive pixels was expressed as integral optical density (IOD) per area. This parameter, expressed in arbitrary units, was compared between groups.

\section{Statistical analysis}

All values of experiments were expressed as means \pm SD. Statistical analysis was performed by using one way twotailed ANOVA test. A probability value less than 0.05 was considered to reflect statistically significant differences.

\section{Results}

Biometrical parameters of experimental rats are summarized in Table 1. Six weeks after the exposure of healthy rats to 25 Gy irradiation, the body weight was significantly lower

Table 1. Biometric parameters of experimental rats

\begin{tabular}{lcc}
\hline & $\begin{array}{c}\text { Wistar controls } \\
(n=12)\end{array}$ & $\begin{array}{c}\text { Wistar irradiated } \\
(n=12)\end{array}$ \\
\hline Body weight $(\mathrm{g})$ & $405 \pm 7$ & $310 \pm 12^{\star *}$ \\
Heart weight $(\mathrm{g})$ & $1.05 \pm 0.01$ & $1.25 \pm 0.25^{\star}$ \\
Left ventricular weight $(\mathrm{g})$ & $0.75 \pm 0.07$ & $0.76 \pm 0.1$ \\
\hline
\end{tabular}

${ }^{*} p<0.05,{ }^{* *} p<0.01$ vs. Wistar controls. as compared to the non-irradiated controls. Furthermore, a small but significant increase of heart weight (with no change in left ventricular weight) was registered when compared to non-irradiated rats.
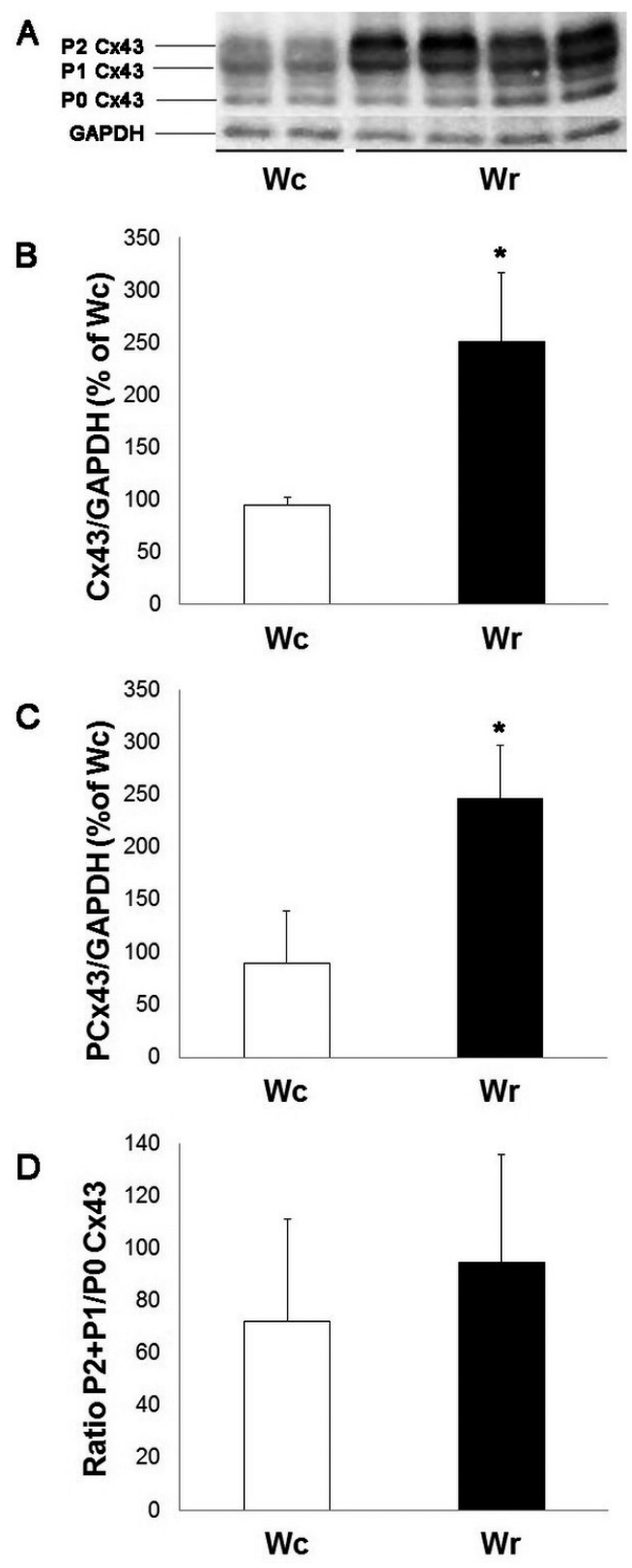

Figure 1. Representative immunoblots (A) and quantitative evaluation of myocardial expression of total $\mathrm{Cx} 43$ protein (B), phosphorylated forms of $\mathrm{Cx} 43$ (C) and ratio of phosphorylated to non-phosphorylated forms of $\mathrm{Cx} 43$ (D) normalized to GAPDH in control (Wc, $n=6)$ and irradiated Wistar rat hearts (Wr, $n=6)$. Note that $\mathrm{Cx} 43$ is expressed in two functional phosphorylated (P1, $\mathrm{P} 2$ ) and one non-phosphorylated (P0) forms. Data are means \pm $\mathrm{SD},{ }^{*} p<0.05$ vs. Wc. 
Irradiation caused significant increase in the expression of total myocardial Cx43, its functional phosphorylated forms as well as ratio of phosphorylated to non-phosphorylated forms of $\mathrm{Cx} 43$ in left ventricles (Fig. 1). In addition,
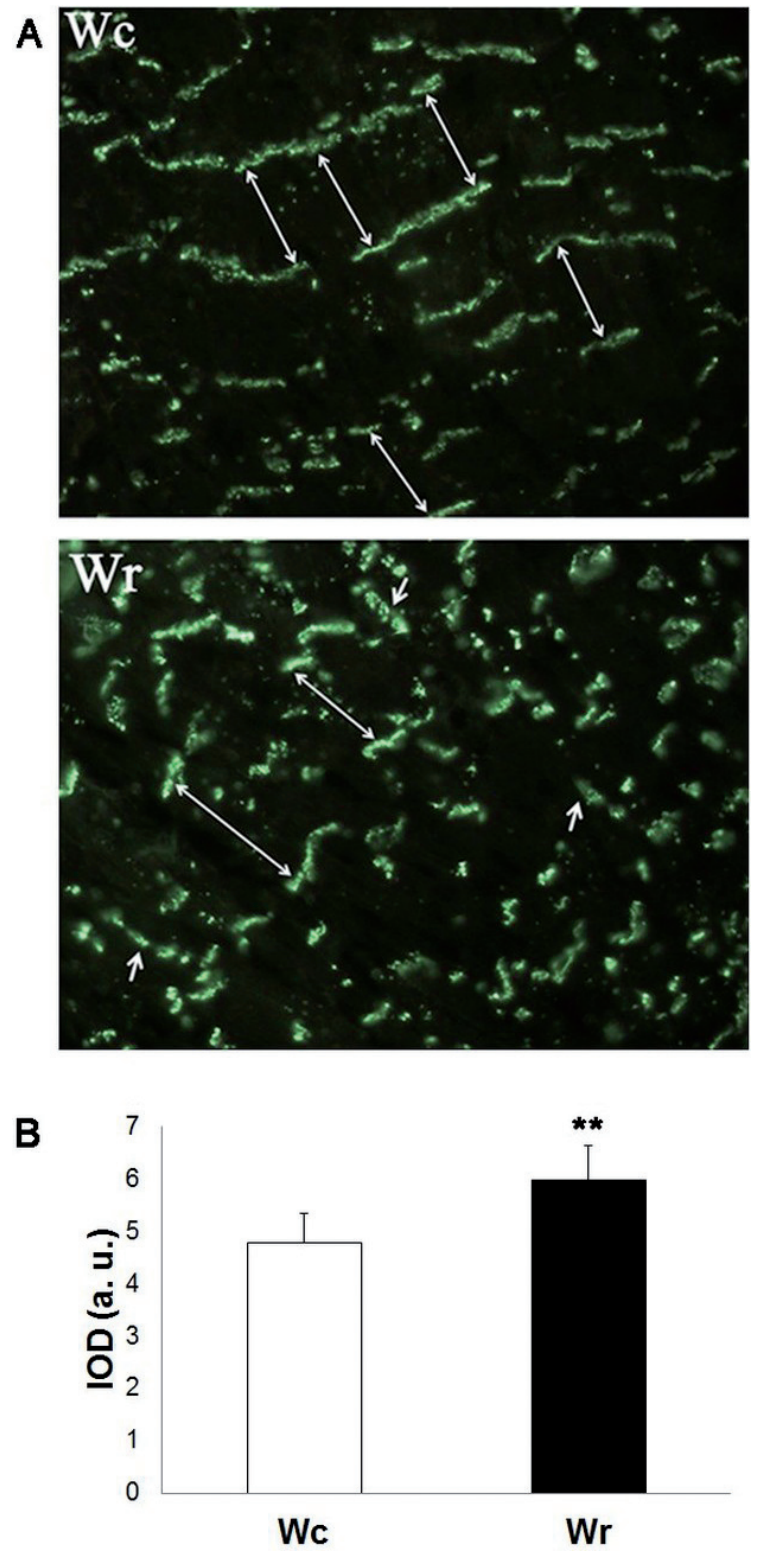

Figure 2. A. Cx43 immunolabeling in the left ventricles of nonirradiated (Wc) and irradiated Wistar rat hearts (Wr). Note the conventional distribution of $\mathrm{Cx} 43$-positive gap junctions predominantly at the intercalated discs (double-head arrows) in Wc. In addition, $\mathrm{Cx} 43$ is distributed on lateral surfaces of the cardiomyocytes (short arrows) of Wr hearts. Objective $\times 40$. B. Quantitative image analysis of the $\mathrm{Cx} 43$ immunofluorescence signal revealed increased integral optical density (IOD) in irradiated compared to non-irradiated rat hearts. Results are the mean \pm SD of 20 images per heart (6 hearts per group). ${ }^{* *} p<0.05 v s$. Wc.

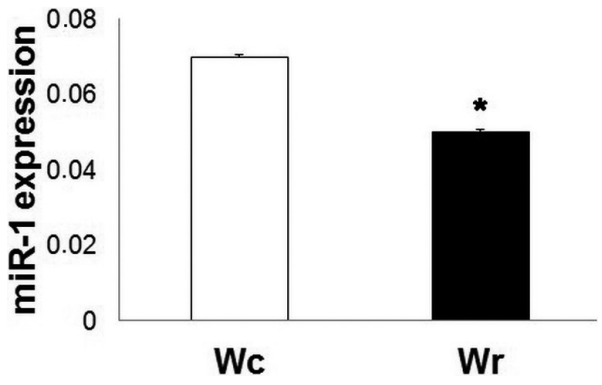

Figure 3. Myocardial expression of miR-1 in control (Wc, $n=6$ ) and irradiated Wistar rat hearts $(\mathrm{Wr}, n=6)$. Endogenous U6 small nuclear RNA (U6snRNA) was used as control for miR-1. Data are means $\pm \mathrm{SD},{ }^{*} p<0.05 v s$. Wc.

moderate abnormalities in cardiomyocyte $\mathrm{Cx} 43$ distribution were also detected by in situ immunolabeling in the irradiated rats. Accordingly, besides the normal pattern of $\mathrm{Cx} 43$-immunopositivity confined to the intercalated discs, some cardiomyocytes exhibited enhanced immunopositive staining on lateral cardiac cell membranes as well (Fig. 2). Quantitative image analysis revealed increased immunopositive signal reflecting Cx43 expression in irradiated rat heart compared to control rats (Fig. 2).

In parallel to post-irradiation related up-regulation of myocardial Cx43 protein, the expression level of miR-1 was significantly reduced in left ventricles compared to nonirradiated controls (Fig. 3). On the other hand, myocardial expression of miR-21 was significantly increased six weeks after the irradiation (Fig. 4).

Expression of both isoforms of PKC, i.e. PKCe and PKC $\delta$ was significantly increased in the left ventricular tissue as determined by Western blotting and shown on Fig. 5 and Fig. 6 six weeks after the exposure of rats to chest irradiation.

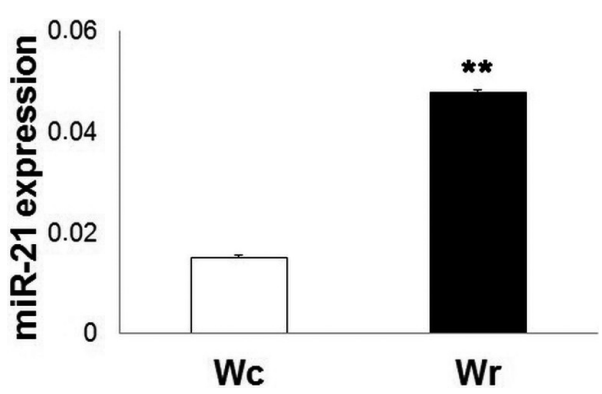

Figure 4. Myocardial expression of miR-21 in control (Wc, $n=6$ ) and irradiated Wistar rat hearts $(\mathrm{Wr}, n=6)$. Endogenous U6 small nuclear RNA (U6snRNA) was used as control for miR-21. Data are means $\pm \mathrm{SD},{ }^{*} p<0.05 v s$. Wc. 


\section{Discussion}

The present study demonstrates the possible implication of myocardial Cx43, miR-1 and miR-21 as well as PKC signalling in post-irradiation response of the rat heart. We showed that in addition to previously reported radiation-induced up-regulation of $\mathrm{Cx} 43$ protein and mRNA in intact as well as infarcted rabbit heart ventricle (Amino et al. 2006), there is an increase of functional phosphorylated forms of $\mathrm{Cx} 43$. Enhanced phosphorylation of $\mathrm{Cx} 43$ may be in part attributed to increased expression of PKCe. Our previous studies suggest that enhanced $\mathrm{Cx} 43$ phosphorylation due to activation of PKC $\varepsilon$ was linked with slowing of myocardial conduction and decreasing susceptibility of diabetic or hypothyroid rat hearts to malignant arrhythmias (Lin et al. 2006, 2008; Bacova et al. 2013). In contrast, reduced expression of PKCE accompanied by decreased $\mathrm{Cx} 43$ phosphorylation in hyperthyroid rat hearts was highly proarrhythmic (Bacova et al. 2013). Enhanced Cx43 expression in post-irradiated rat heart was also detected by quantitative image analysis of in situ immunolabeling of $\mathrm{Cx} 43$. Moderate alterations in topology of $\mathrm{Cx} 43$ likely indicate early stage of myocardial remodelling, as previously shown in experimental hypertension (Radosinska et al. 2011, 2013). Lateralization of Cx43 in chronic models of cardiac injury is often associated with myocardial hypertrophy (Lin et al. 2008; Radosinska et al. 2011). It is likely that to compensate irradiation-related adverse effects, the heart activates processes resulting in hypertrophy of individual cardiomyocytes. Nevertheless, left ventricular weight was not changed in irradiated rats suggesting that myocardial hypertrophy was not pronounced
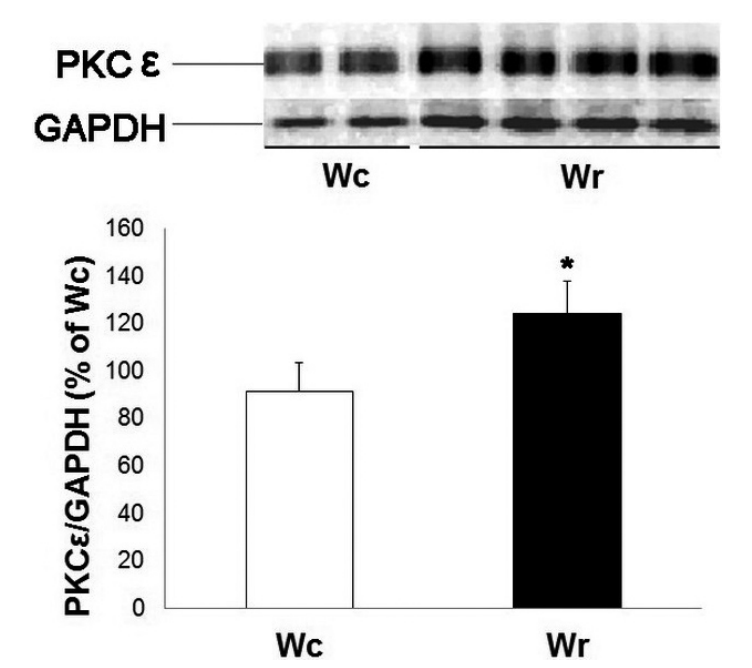

Figure 5. Representative immunoblots (upper panel) and quantitative evaluation of myocardial expression of PKC $\varepsilon$ normalized to GAPDH in control (Wc, $n=6$ ) and irradiated Wistar rat hearts (Wr, $n=6)$. Data are means $\pm \mathrm{SD},{ }^{\star} p<0.05 v s$. Wc.
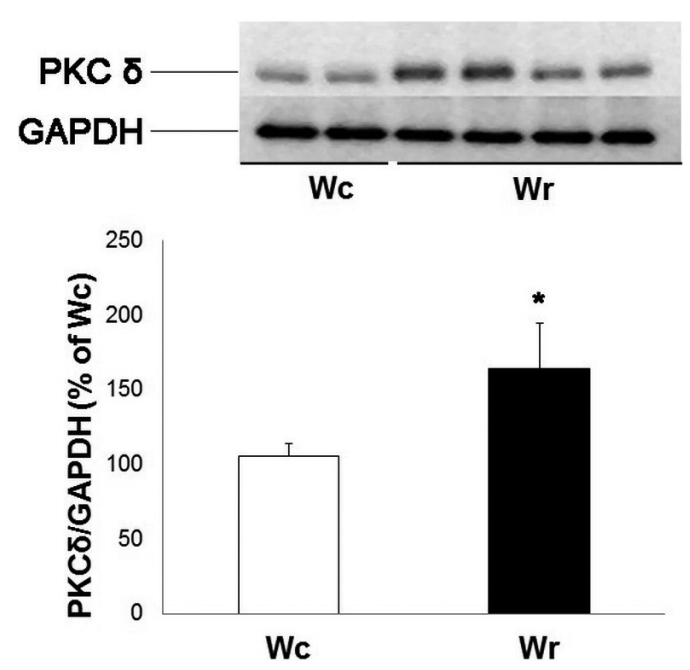

Figure 6. Representative immunoblots (upper panel) and quantitative evaluation of myocardial expression of PKC $\delta$ normalized to GAPDH in control (Wc, $n=6$ ) and irradiated Wistar rat hearts (Wr, $n=6)$. Data are means $\pm \mathrm{SD},{ }^{*} p<0.05 v$ s. Wc.

likewise observed alterations in topology of $\mathrm{Cx} 43$. On the other hand, heart weight was moderately elevated likely on the account to right ventricle of the heart. This assumption is supported by the fact that the ratio of right to left ventricles was increased in this model of rat irradiation (Mezesova et al. 2014). The issue needs to be addressed more in details in further studies.

In the present study, we demonstrated that up-regulation of $\mathrm{Cx} 43$ was associated with suppression of miR-1. Previous studies have shown that over-expression of miR-1 was correlated with reduced $\mathrm{Cx} 43$ protein expression in viral myocarditis (Xu et al. 2012) while down-regulation of miR-1 by Ang II stimulation was associated with increased $\mathrm{Cx} 43$ expression (Curio et al. 2013). Interestingly, irradiation of the heart resulted in protection from malignant arrhythmias (Amino et al. 2006) and hence suppression of miR-1 exerted antiarrhythmic potential most likely by targeting GJA1 (which encodes Cx43) and KCNJ2 (which encodes the $\mathrm{K}^{+}$channel subunit Kir2.1) (Yang et al. 2007). Thus, it appears that irradiation-induced antiarrhythmic effects can be in part attributed to down-regulation of miR-1 which may be linked with up-regulation of $\mathrm{Cx} 43$ and $\mathrm{PKC} \varepsilon$ related phosphorylation. In contrast, miR-1 overexpression inhibits electrical coupling and depolarized cardiac cell membrane by post-transcriptional repression of GJA1 and KCNJ2 which likely accounts for its arrhythmogenic potential (Yang et al. 2007). Pro-arrhythmogenic effect of elevated miR-1 in infarcted heart was attenuated by its down-regulation induced with propranolol (Lu et al. 2009). Over-expression of miR-1 also exacerbated cardiac ischemia-reperfusion injury (Pan et al. 2012) and impaired cardiac contractile function in 
mouse models (Ai et al. 2012). Taken together, it appears that irradiation-induced suppression of miR-1 might be beneficial for the heart. Noteworthy, miR-1 is released to blood circulation thus it has a potential to be a novel biomarker of cardiac injury (Ai et al. 2010) and possibly proarrhythmogenic state.

Compared to suppression of $\mathrm{miR}-1$, ionizing radiation has been reported to stimulate expression of miR-21 in various types of mammalian cells (Shi et al. 2012), similar to our results in the heart tissue. Interestingly, miR-21 is over-expressed in almost all types of human cancers and it has been suggested that miR-21 underlies radioresistance of cancer because its inhibition increases radiosensitivity via activation of PTEN promoting the apoptosis in tumor cells (Liu et al. 2014). In parallel to the increased levels of miR-21, there was an increase of both expression and activity of MMP-2 in left ventricles of irradiated rat hearts compared to non-irradiated (Barancik et al. 2013). These activation of cardiac remodelling in response to irradiation which may accelerate over time since miR-21 activates fibroblasts (Thum et al. 2008; Bauersachs 2012; van Rooij et al. 2012) and enhanced proteolytic activity of MMP-2 promotes fibroblast migration (Bauersachs 2012). Moreover, it has been recently identified that fibroblast exosomalderived miR-21 is like a potent paracrine acting RNA molecule that induces cardiomyocyte hypertrophy (Bang et al. 2014). In response to stress, the heart undergoes an extensive cardiac remodelling resulting in cardiac hypertrophy and fibrosis that over time contribute to heart failure. Delayed inhibition of miR-21 after myocardial infarction attenuates reactive fibrosis and heart failure development (Bauersachs 2012). However, the anti-apoptotic and proliferation promoting effects of miR-21 may be pro-survival to cardiac tissue in early adaptation period in response to radiation-induced injury.

In the context of alterations of miR-21 it should be noted that we have found significant increase of $\mathrm{PKC} \delta$ expression six weeks after irradiation. $\mathrm{PKC} \delta$ is a serine/threonine kinase, which plays a key role in growth regulation, tissue remodelling and cell apoptosis (Steinberg 2004). PKC $\delta$ was up-regulated in spontaneously hypertensive rat hearts (Radosinska et al. 2013) and in pressure-overloaded myocardium (reviewed in Steinberg 2004) suggesting its involvement in the induction of compensatory hypertrophy. Moreover, PKC $\delta$ acts as a switch between cardiomyocyte hypertrophy and apoptosis and chronic PKC $\delta$ over-expression facilitated cardiomyocyte apoptosis and contractile dysfunction (Steinberg 2004). Increased expression of both miR-21 and PKC $\delta$ in response of the heart to irradiation injury suggests their implication in processes of myocardial remodelling.

In summary, our results show that a single dose of chest irradiation triggers myocardial alterations six weeks later which most likely reflect adaptation of the heart to radiation injury (Slezak et al. 2015). These myocardial adaptive changes could have beneficial as well as adverse consequences. Importantly, single dose of irradiation exhibits potential to enhance cardiac $\mathrm{Cx} 43$-mediated cell-cell coupling and communication via down-regulation by miR-1 rendering protection of the heart against malignant arrhythmias. Further investigations are needed to determine the cause and effect relationship of these observations.

Acknowledgements. This study was supported by APVV 0241/11 and VEGA grants 2/0076/16, 2/00167/15, 2/0021/15.

Conflict of interest. The authors declare no conflict of interest.

\section{References}

Azzam E. I., de Toledo S. M., Little J. B. (2003): Expression of connexin 43 is highly sensitive to ionizing radiation and other environmental stresses. Cancer Res. 63, 7128-7135

Amino M., Yoshioka K., Tanabe T., Tanaka E., Mori H., Furusawa Y., Zareba W., Yamazaki M., Nakagawa H., Honjo H. et al. (2006): Heavy ion radiation up-regulates connexin 43 and ameliorates the arrhythmogenic substrates in rabbit hearts after myocardial infarction. Cardiovasc. Res. 72, 412-421 http://dx.doi.org/10.1016/j.cardiores.2006.09.010

Amino M., Yoshioka K., Fujibayashi D., Hashida T., Furusawa Y., Zareba W., Ikari Y., Tanaka E., Mori H., Inokuchi S. et al. (2010): Year-long upregulation of connexin43 in rabbit hearts by heavy ion irradiation. Am. J. Physiol. Heart Circ. Physiol. 298, H1014-1021 http://dx.doi.org/10.1152/ajpheart.00160.2009

Ai J., Zhang R., Li Y., Pu J., Lu Y., Jiao J., Li K., Yu B., Li Z., Wang R. et al. (2010): Circulating microRNA-1 as a potential novel biomarker for acute myocardial infarction. Biochem. Biophys. Res. Commun. 391, 73-77 http://dx.doi.org/10.1016/j.bbrc.2009.11.005

Ai J., Zhang R., Gao X., Niu H.F., Wang N., Xu Y., Li Y., Ma N., Sun LH., Pan Z.W. et al. (2012): Overexpression of microRNA-1 impairs cardiac contractile function by damaging sarcomere assembly. Cardiovasc. Res. 95, 385-393 http://dx.doi.org/10.1093/cvr/cvs196

Bacova B., Viczenczova C, Zurmanova J., Kasparova D., Knezl V., Radosinska J., Benová T., Pavelka S., Soukup T., Tribulová N. (2013): Susceptibility of rats with altered thyroid status to malignant arrhythmias is primarily related to myocardial levels of connexin- 43 and can be partially ameliorated by supplementation with red palm oil. Exp. Clin. Cardiol. 18, (Suppl A), 41-46

Bang C., Batkai S., Dangwal S., Gupta S.K., Foinquinos A., Holzmann A., Just A., Remke J., Zimmer K., Zeug A. et al. (2014): Cardiac fibroblast-derived microRNA passenger strandenriched exosomes mediate cardiomyocyte hypertrophy. J. Clin. Invest. 124, 2136-2146 http://dx.doi.org/10.1172/JCI70577

Barancik M., Okruhlicova L., Fogarassyova M., Bartekova M., Slezak J. (2013): Mediastinal irradiation modulates myocardial 
and circulating matrix metalloproteinases. Exper. Clin. Cardiol. 18, (Suppl. A), 37-40

Bauersachs J. (2012): miR-21: a central regulator of fibrosis not only in the broken heart. Cardiovasc. Res. 96, 227-229 http://dx.doi.org/10.1093/cvr/cvs200

Curcio A., Torella D., Iaconetti C., Pasceri E., Sabatino J. Sorrentino S., Giampà S., Micieli1 M., Polimeni A., Henning B. J. et al. (2013): MicroRNA-1 downregulation increases connexin 43 displacement and induces ventricular tachyarrhythmias in rodent hypertrophic hearts. PLoS One 8, e70158 http://dx.doi.org/10.1371/journal.pone.0070158

Jansen J. A., van Veen T. A., de Jong S., van der Nagel R., van Stuijvenberg L., Driessen H., Labzowski R., Oefner C. M., Bosch A. A., Nguyen T. Q. et al. (2012): Reduced Cx43 expression triggers increased fibrosis due to enhanced fibroblast activity. Circ. Arrhythm. Electrophysiol. 5, 380-390 http://dx.doi.org/10.1161/CIRCEP.111.966580

Khan S., Ansarullah, Kumar D., Jaggi M., Chauhan S. C. (2013): Targeting microRNAs in pancreatic cancer: microplayers in the big game. Cancer Res. 15, 6541-6547 http://dx.doi.org/10.1158/0008-5472.CAN-13-1288

Kukreja R. C., Yin C., Salloum F. N. (2011): MicroRNAs: new players in cardiac injury and protection. Mol. Pharmacol. 80, 558-564 http://dx.doi.org/10.1124/mol.111.073528

Lin H., Ogawa K., Imanaga I., Tribulova N. (2006): Remodeling of connexin 43 in the diabetic rat heart. Mol. Cell. Biochem. 290, 69-78 http://dx.doi.org/10.1007/s11010-006-9166-y

Lin H., Mitasikova M., Dlugosova K., Okruhlicova L., Imanaga I., Ogawa K., Weismann P., Tribulova N. (2008): Thyroid hormones suppress epsilon-PKC signalling, down-regulate connexin-43 and increase lethal arrhythmia susceptibility in non-diabetic and diabetic rat hearts. J. Physiol. Pharmacol. 59, 271-285

Liu J., Zhu H., Yang X., Ge Y., Zhang C., Qin Q., Lu J., Zhan L., Cheng H., Sun X. (2014): MicroRNA-21 is a novel promising target in cancer radiation therapy. Tumour Biol. 35, 3975-3979 http://dx.doi.org/10.1007/s13277-014-1623-8

Lu Y., Zhang Y., Shan H., Pan Z., Li X., Li B., Xu C., Zhang B., Zhang F., Dong D., Song W., Qiao G., Yang B. (2009): MicroRNA-1 downregulation by propranolol in a rat model of myocardial infarction: a new mechanism for ischaemic cardioprotection. Cardiovasc. Res. 84, 434-441

http://dx.doi.org/10.1093/cvr/cvp232

Mézešová L., Vlkovičová J., Kaločayová B., Jendruchová V., Barančík M., Fülöp M., Slezák J., Babál P., Janega P., Vrbjar N. (2014): Effects of $\gamma$-irradiation on $\mathrm{Na}, \mathrm{K}$-ATPase in cardiac sarcolemma. Mol. Cell. Biochem. 388, 241-247 http://dx.doi.org/10.1007/s11010-013-1915-0

Pan Z., Sun X., Ren J., Li X., Gao X., Lu CH., Zhang Y., Sun H., Wang Y., Wang H., Wang J., Xie L., Lu Y., Yang B. (2012): miR-1 exacerbates cardiac ischemia-reperfusion injury in mouse models. PLoS ONE 7, e50515 http://dx.doi.org/10.1371/journal.pone.0050515

Quinn E. M., Wang J., Redmond H. P. (2012): The emerging role of microRNA in regulation of endotoxin tolerance. J. Leukoc. Biol. 91, 721-727 http://dx.doi.org/10.1189/jlb.1111571

Radosinska J., Bacova B., Bernatova I., Navarova J., Zhukovska A., Shysh A., Okruhlicova L., Tribulova N. (2011): Myocardial NOS activity and connexin-43 expression in untreated and omega-3 fatty acids-treated spontaneously hypertensive and hereditary hypertriglyceridemic rats. Mol. Cell. Biochem. 347, 163-173 http://dx.doi.org/10.1007/s11010-010-0625-0

Radosinska J., Bacova B., Knezl V., Benova T., Zurmanova J., Soukup T., Arnostova P., Slezak J., Gonçalvesova E., Tribulova N. (2013): Dietary omega-3 fatty acids attenuate myocardial arrhythmogenic factors and propensity of the heart to lethal arrhythmias in a rodent model of human essential hypertension. J. Hypertens. 31, 1876-1885

http://dx.doi.org/10.1097/HJH.0b013e328362215d

Salameh A., Dhein S. (2005): Pharmacology of Gap junctions. New pharmacological targets for treatment of arrhythmia, seizure and cancer? Biochim. Biophys. Acta 1719, 36-58 http://dx.doi.org/10.1016/j.bbamem.2005.09.007

Severs N. J., Bruce A. F., Dupont E., Rothery S. (2008): Remodelling of gap junctions and connexin expression in diseased myocardium. Cardiovasc. Res. 80, 9-19 http://dx.doi.org/10.1093/cvr/cvn133

Shi Y., Zhang X., Tang X., Wang P., Wang H., Wang Y. (2012): MiR21 is continually elevated long-term in the brain after exposure to ionizing radiation. Radiat. Res. 177, 24-28 http://dx.doi.org/10.1667/RR2764.1

Slezak J., Kura B., Ravingerova T., Tribulova N., Okruhlicova L., Barancik M. (2015): Mechanisms of cardiac radiation injury and potential preventive approaches. Can. J. Physiol. Pharmacol. 27, 1-17

Steinberg S. F. (2004): Distinctive activation mechanisms and functions for protein kinase C $\delta$. Biochem. J. 384, 449-459 http://dx.doi.org/10.1042/BJ20040704

Tang Y., Zheng J., Sun Y., Wu Z., Liu Z., Huang G. (2009): MicroRNA-1 regulates cardiomyocyte apoptosis by targeting Bcl-2. Int. Heart J. 50, 377-387 http://dx.doi.org/10.1536/ihj.50.377

Thum T., Gross C., Fiedler J., Fischer T., Kissler S., Bussen M., Galuppo P., Just S., Rottbauer W., Frantz S. et al. (2008): MicroRNA- 21 contributes to myocardial disease by stimulating MAP kinase signalling in fibroblasts. Nature 456, 980-984 http://dx.doi.org/10.1038/nature07511

Toldo S., Das A., Mezzaroma E., Chau V. Q., Marchetti C., Durrant D., Samidurai A., Van Tassell B. W., Yin C., Ockaili R. A. et al. (2014): Induction of microRNA-21 with exogenous hydrogen sulfide attenuates myocardial ischemic and inflammatory injury in mice. Circ. Cardiovasc. Genet. 3, 311-320 http://dx.doi.org/10.1161/CIRCGENETICS.113.000381

Tribulová N., Knezl V., Okruhlicová L., Slezák J. (2008): Myocardial gap junctions: Targets for novel approaches in the prevention of life-threatening cardiac arrhythmias. Physiol. Res. 57, (Suppl. 2), S1-13

Tribulova N., Szeiffova Bacova B., Benova T., Viczenczova C. (2015): Can we protect from malignant arrhythmias by modulation of cardiac cell-to-cell coupling? J. Electrocardiol. 48, 434-440 http://dx.doi.org/10.1016/j.jelectrocard.2015.02.006 van Rooij E., Purcell A. L., Levin A. A. (2012): Developing microRNA therapeutics. Circ Res. 3, 496-507 
http://dx.doi.org/10.1161/CIRCRESAHA.111.247916

Yang B., Lin H., Xiao J., Lu Y., Luo X., Li B., Zhang Y., Xu C., Bai Y., Wang H., Chen G., Wang Z. (2007): The muscle-specific microRNA miR-1 regulates cardiac arrhythmogenic potential by targeting GJA1 and KCNJ2. Nat. Med. 13, 486-491 http://dx.doi.org/10.1038/nm1569

Yin C., Salloum F., Kukreja R. C. (2009): A novel role of microRNA in ischemic preconditioning: upregulation of eNOS and HSP70. Circ. Res. 104, 572-575
http://dx.doi.org/10.1161/CIRCRESAHA.108.193250

Xu H. F., Ding Y. J., Shen Y. W., Xue A. M., Xu H. M., Luo CH. L., Li B. X., Liu Y. L., Zhao Z. Q. (2012): MicroRNA-1 represses Cx43 expression in viral myocarditis. Mol. Cell Biochem. 362, 141-148 http://dx.doi.org/10.1007/s11010-011-1136-3

Received: July 17, 2015

Final version accepted: September 2, 2015

First published online: February 2, 2016 